\title{
Feature Extraction of Simulated Fault Signals in Stator Windings of a High Voltage Motor and Classification of Faulty Signals
}

\author{
Jae-Jun Park ${ }^{1, a}$ and In-Bum Jang ${ }^{2}$
}

\begin{abstract}
In the case of the fault in stator windings of a high voltage motor, it facilitates certain destructive characteristics in insulations. This will result in a decreased reliability in power supplies and will prevent the generation of electricity, which will result in huge economic losses. This study simulates motor windings using normal windings and four faulty windings for an actual fault in stator winding of a high voltage motor. The partial discharge signals produced in each faulty winding were measured using an $80 \mathrm{PF}$ epoxy/mica coupler sensor. In order to quantified signal waves as a way of feature extraction for each faulty signal, the signal wave of winding was quantified to measure the degree of skewness shape and kurtosis, which are both types of statistical parameters, using a discrete wavelet transformation method for each faulty type. Wave types present different types for each faulty type, and the skewness and kurtosis also present different quantified values. The result of feature extraction was used as a preprocessing stage to identify a certain fault in stator windings. It is evident that the type of faulty signals can be classified from the test results using faulty signals that were randomly selected from the signal, which was not applied in the training after the training and learning period, by applying it to a back-propagation algorithm due to the supervising and learning method in a neural network in order to classify the faulty type. This becomes an important basis for studying diagnosis methods using the classification of faulty signals with a feature extraction algorithm, which can diagnose the fault of stator windings in the future.
\end{abstract}

Key Words : High voltage motor, Stator winding, Wavelet transform, Feature extraction, Neural network

\section{INTRODUCTION}

Because a high voltage motor used in a power plant as an important auxiliary equipment requires a high starting current and rotation power based on its operational characteristics, there are some possibilities in weakening or

1. Department of Electrical Electronic Engineering, Joongbu University

(101 Daehakro Chubu-myeon, Geumsan-gun, Chungnam, Korea)

2. Department of Electrical Engineering, Kwangwoon University

a. Corresponding Author: jjpark@joongbu.ac.kr

접수일자 : 2005. 8. 22

1 차 심사 : 2005. 9. 7

심사완료 : 2005. 9. 13 destroying insulations due to the accumulation of deterioration in windings that can be caused by electrical and mechanical fatigues in a motor for a long time of operation.

The fault in windings of a high voltage motor leads to destroy insulations and causes huge economic losses due to the lowering reliability in power supplies and stopping the generation of electricity. It is possible to contribute power industries if the type of faults, fault positions, and degrees of deteriorations can be detected before the insulation destroy occurred. Partial discharge measurement methods have been studied for a long time to investigate the type of faults and degrees of deteriorations by detecting these faults and conducted to apply it 
in practical uses[1-4].

A $6.6 \mathrm{kV}$ class high voltage motor was used in this study, and faulty signals were generated at a faulty position of the stator winding due to the partial discharge when a high electric field was applied. A discrete wavelet transformation method was used to identify faulty signals generated in a certain faulty winding. The characteristics of wave can be extracted as a quantified manner with statistical parameters of faulty signals, such as skewness, kurtosis, maximum value, average value, and distribution value[5,6]. In addition, spectrums were analyzed by transforming it from the function, which was generated in a time domain in each faulty winding, to the function, which was generated in a frequency domain. In order to classify various faulty signals, statistical parameters, which were extracted in its features using a preprocessing stage of neural network inputs. Five faulty signals given by some simulated faulty windings, such as normal winding (No. 1), r internal discharge fault (No. 2), creeping discharge fault (No. 3), 1 wire short fault (No. 4), corona prevention tape elimination fault (No. 5), were classified using learning and training activities of a neural network.

\section{EXPERIMENT}

\subsection{Fabrication of simulated faults in stator windings of a high voltage motor}

Although faultless windings are produced in an actual field, faults inevitably occurred. This is due to the fact that the insulation material will inevitably deteriorate according to the electrical stress, mechanical stress, thermal and environmental conditions. Based on these conditions, the utmost actually simulated fault was fabricated with using the advice of several experts and manufacturing companies. As shown in Fig. 1, a normal winding and four faulty windings were fabricated.

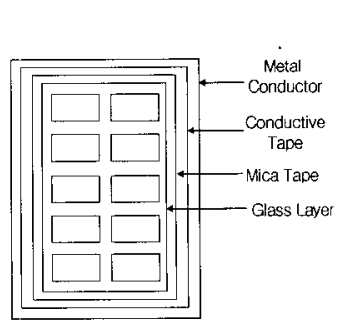

(1) No. 1

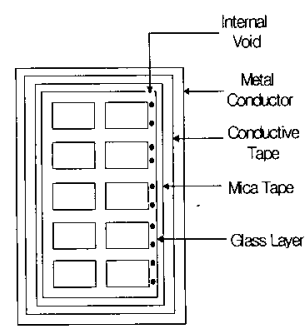

(2) No. 2

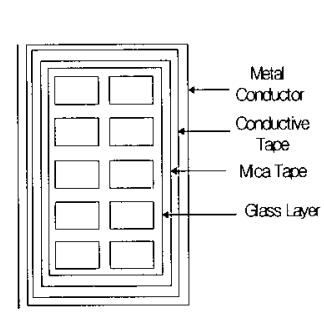

(3) No. 3

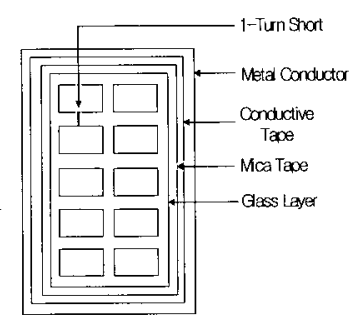

(4) No. 4

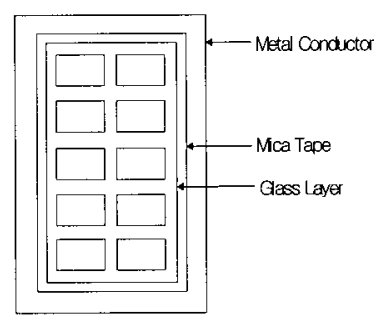

(5) No. 5

Fig. 1. Types of simulated fault windings.

Table. 1. Symbols of simulated faulty windings.

\begin{tabular}{|c|c|}
\hline Symbol & Types of Simulation fault \\
\hline No. 1 & Normal state Winding \\
\hline No. 2 & Internal Fault Winding \\
\hline No. 3 & Creeping Discharge Winding \\
\hline No. 4 & 1-Turn Short Fault Winding \\
\hline No. 5 & Non-Corona Tape Fault Winding \\
\hline
\end{tabular}

\subsection{Obtaining partial discharge faulty signals}

The high voltage generator (Tettex Instruments, Switzer) presented in Fig. 2 was used to generate and apply a high voltage to the simulated faulty stator winding. For the measurement of partial discharge signals, the waveform of the partial discharge pulse that was generated from the simulated stator winding 


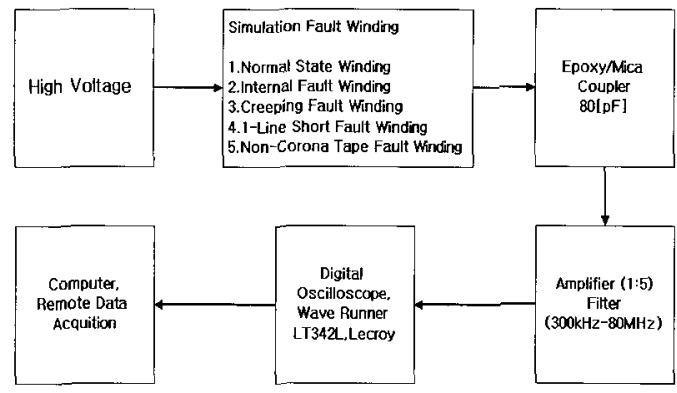

Fig. 2. Configurations of the experiment.

was measured using an epoxy-mica coupler (80 $\mathrm{pF}$ ). The voltage to the stator used in the measurement of the waveform of the partial discharge using an epoxy-mica coupler was applied up to $12 \mathrm{kV}$ (180\% of the $6.6 \mathrm{kV}$ class) to the $6.6 \mathrm{kV}$ class and $1,000 \sim 1,500 \mathrm{~kW}$ winding by increasing it $1 \mathrm{kV} / \mathrm{min}$, and then the applied voltage was maintained as a constant value. The signal at the output port of the partial discharge coupler can be amplified using a self-designed transformer (1:5). In addition, a band filter where the largest signal was generated at $300 \mathrm{kHz} \sim 80 \mathrm{MHz}$ was used, and the only signal passing through the band filter can be input in a digital oscilloscope.

The partial discharge signal input to the input port of a digital oscilloscope (Wave Runner LT342L, Lecroy) can be displayed as a type of analog waveform, and the final partial discharge pulse waveform can be obtained from a computer, in which the signal was transmitted using a remote network through an $\mathrm{A} / \mathrm{D}$ converter, which has a $50 \mathrm{MS} / \mathrm{s}$ sampling phase, using an interface lan card with $0.5 \mu \mathrm{s}, 1000$ points data.

The obtained data was analyzed using a FFT (Fast Fourier Transform) after filtering it using Matlab 6.5. Feature extraction was performed by applying various statistical parameters, such as maximum value, average value, distribution value, skewness, and kurtosis, as a process for the extraction of patterns. Feature extraction and frequency analysis were applied for each fault, and the extraction results were used as a preprocessing stage of neural networks. In addition, a back-propagation algorithm was used as a neural network for the signal classification method where training and learning were applied using a forced supervising and learning method, and various simulated faulty signals were classified.

\section{RESULTS}

\subsection{Feature Extraction[5-7,9,10]}

Because the applied voltage was configured as the rated voltage of $6.6 \mathrm{kV}, 1,000 \sim 1,500 \mathrm{~kW}$ winding for the simulated fault winding, $12 \mathrm{kV}$ that is $180 \%$ of the rated voltage was applied to measure the simulated partial discharge pulse signal for the No. 1 No. 5 different signals using a digital oscilloscope. A frequency analysis was applied using feature extraction parameters and FFT by applying a wavelet transformation for the waveform of the epoxy-mica coupler output signal.

\subsubsection{No. 1 (Normal state winding signal)}

An oscilloscope, which has a high current pulses and data processing rate, can measure a single pulse waveform from several ns to tens ns/div. Figure 3(a) and (b) present the results of the partial discharge waveform of the normal state in a time domain and the spectrum transformation in a frequency domain for the waveform. The frequency range was $2.5 \mathrm{MHz}$ $15 \mathrm{MHz}$, and three different dominant central frequencies, such as $5 \mathrm{MHz}, 7 \mathrm{MHz}$, and 12 $\mathrm{MHz}$, existed. Figure 4 presents the waveform in the normal state in which a wavelet transform level-2 was applied. In addition, the skewness (SK) and kurtosis (KU) that present quantified statistical parameters for the pattern of waveform were recorded as .3 .27 and 11.86 , respectively. 


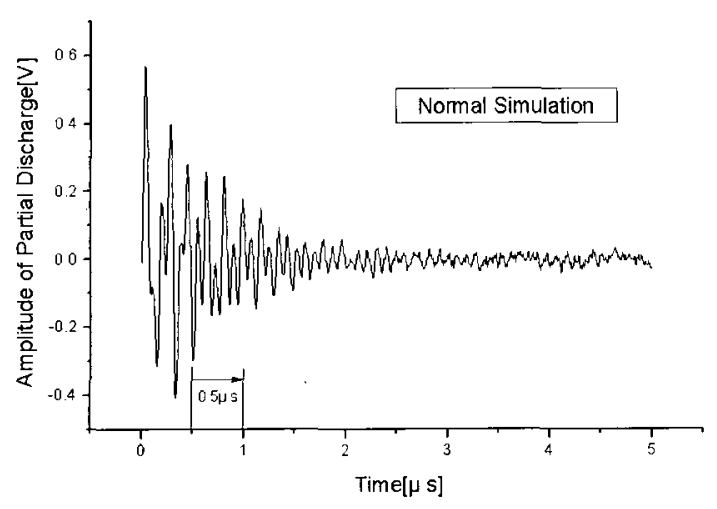

(a) Pulse waveform of the normal winding

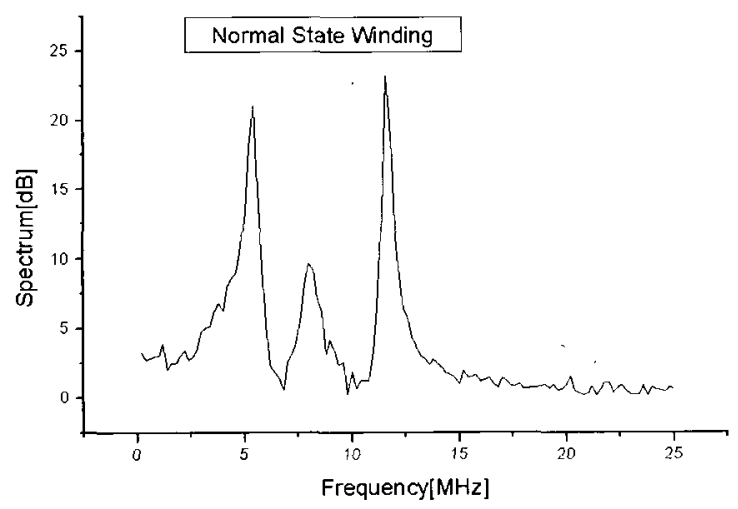

(b) Spectrum analysis

Fig. 3. PD pulse waveform and FFT analysis of the normal winding.

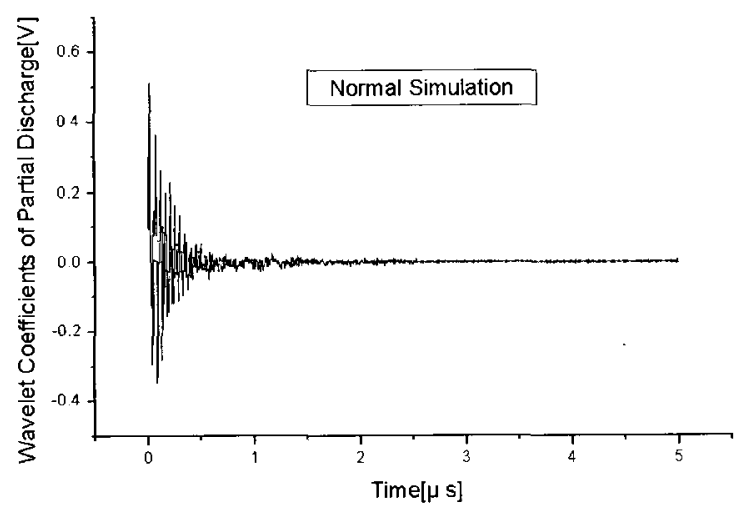

Fig. 4. Wavelet transformation level-2 application of the normal winding $(\mathrm{SK}=3.27, \mathrm{KU}$ $=11.86$ ).

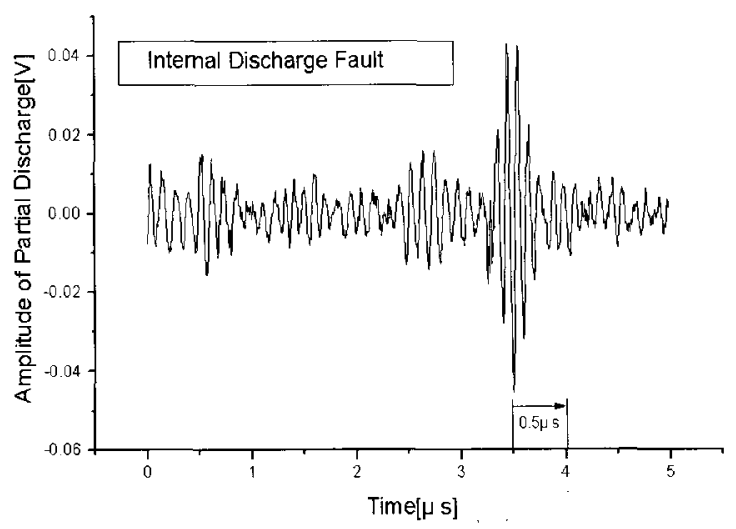

(a) winding

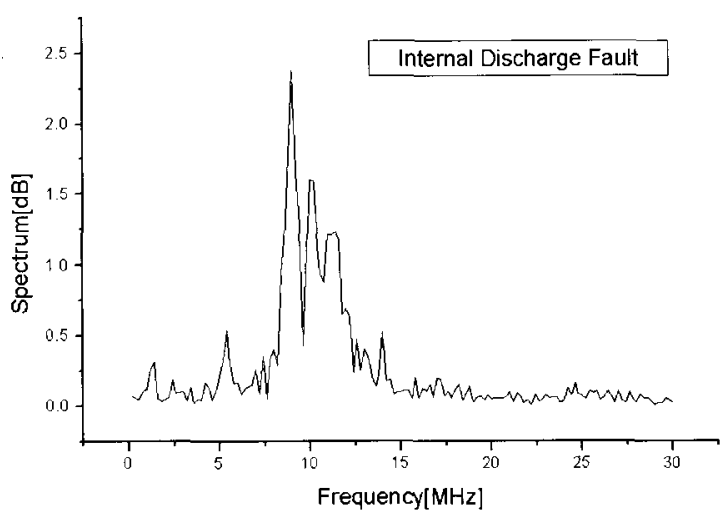

(b) Spectrum analysis

Fig. 5. PD pulse waveform and FFT analysis of the internal discharge winding.

\subsubsection{No. 2 (Internal discharge fault signal)}

Figure 5(a) and (b) present the spectrum analysis results for the partial discharge pulse and its waveform in a time domain for the simulated winding of the internal discharge. The partial discharge waveform in the normal state was configured as a function, which presents an exponentially damped waveform. However, the waveform existed in several large and small discharge waveforms as the waveform of the internal discharge. It is evident that the waveform was generated due to the internal discharge where the waveform was produced from the approaching time of the propagated waveform or multiple pulses from other discharge pulses when electric fields were applied 


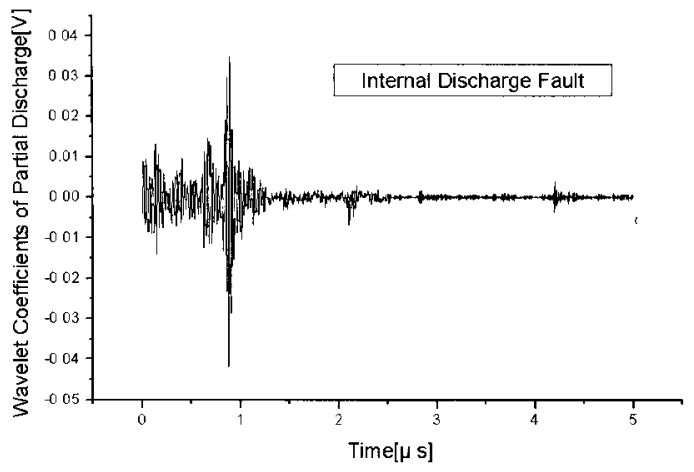

Fig. 6. Wavelet transformation level-2 application of the internal discharge winding $(\mathrm{SK}=$ 2.6, $\mathrm{KU}=8.1$ ).

to several voids that existed inside the insulator at the same time. Figure 5(b) presents the transformation result from a time domain to a frequency domain. The frequency range was 7.5 $\mathrm{MHz} \sim 13 \mathrm{MHz}$, and a multiple waveform existed for $5 \mu \mathrm{s}$ where the central frequency was 10 $\mathrm{MHz}$.

Figure 6 presents the results of the wavelet transform level-2 application for the waveform of the partial discharge pulse. As shown in Fig. 6 , several multiple pulse waveforms existed in the range of $5 \mu_{\mathrm{s}}$ where a wavelet transformation was applied. In addition, the distribution center of the skewness, which is a type of statistical parameter, was dispersed, and the concentration was lowered. The values of SK and KU were 2.6 and 8.1 , respectively.

\subsubsection{No. 3 (Creeping discharge fault signal)}

Creeping discharge, which is the term given to the process for surface discharge in a wide sense. The test performed in this study was conducted without any corruptions on the surface. Figure 7(a) presents a waveform of the partial discharge pulse in a time domain for the creeping discharge. This waveform was damped as an exponential function. In addition, the duration time was as short as about $0.5 \mathrm{~s}$, but the waveform in the normal state was a type of exponential function, which has an easiness

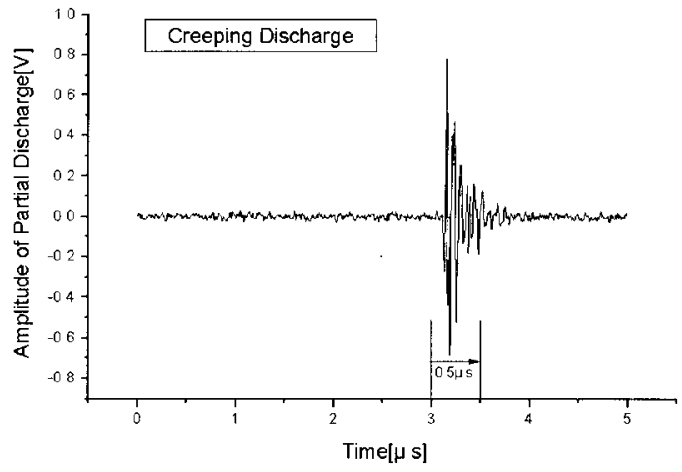

(a) Pulse waveform of the creeping discharge winding

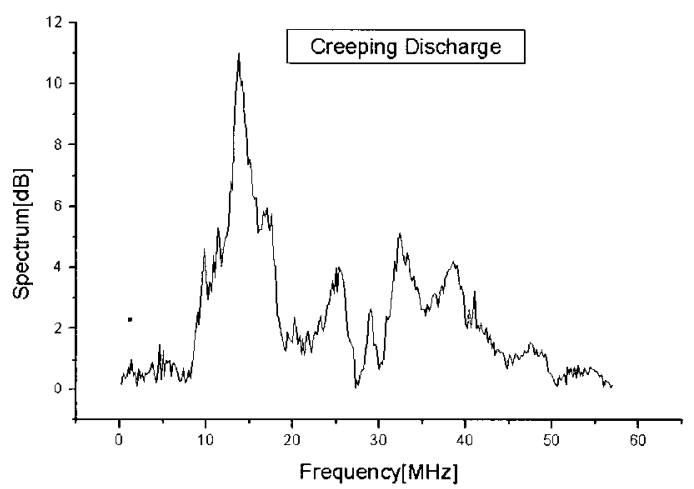

(b) Spectrum analysis

Fig. 7. PD pulse waveform and FFT analysis of the creeping discharge winding.

gradient and a duration time of about $2 \mathrm{~s}$. The duration time in the normal state was four times longer than that of the normal winding.

Figure $7(\mathrm{~b})$ presents the results of the transformation from a time domain to a frequency domain where the frequency range was $8.8 \mathrm{MHz}$ $\sim 50 \mathrm{MHz}$, and the central frequency was 12 $\mathrm{MHz}$ as a large spectrum. Figure 8 presents the results of the transformation from the waveform of the partial discharge pulse illustrated in Fig. 7 (a) to the waveform using a wavelet transform level-2. The waveform presented the a quantified partial discharge pulse with $\mathrm{SK}=5.4$ and $\mathrm{KU}=31.4$. 


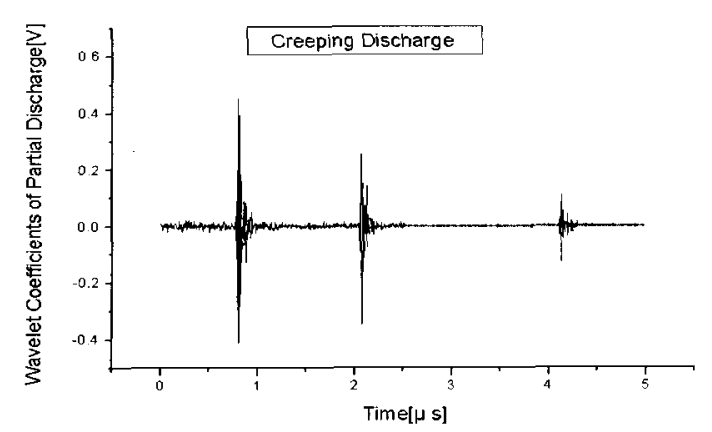

Fig. 8. Wavelet transformation level-2 application of the creeping discharge winding shown in Fig. 7(a)(SK=5.4 KU=31.4).

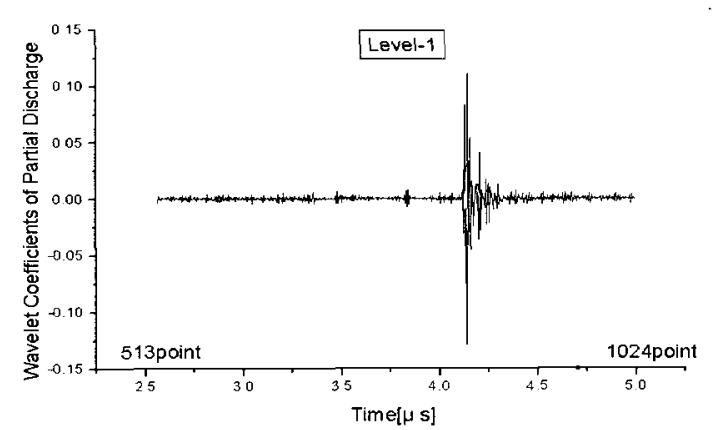

(a) Level-1(25 MHz $\sim 50 \mathrm{MHz})$

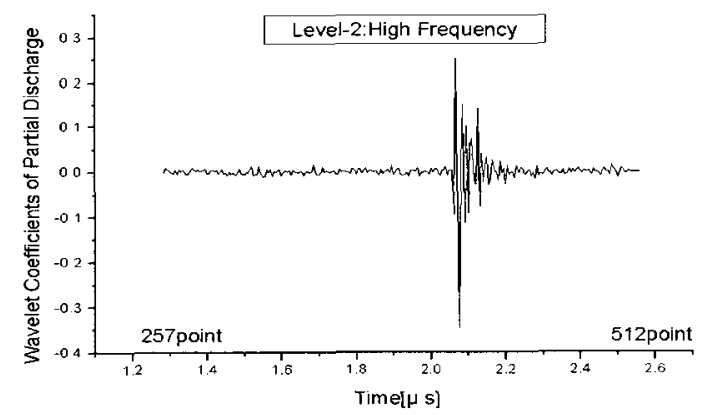

(b) Level-2(25 MHz $-12.5 \mathrm{MHz})$

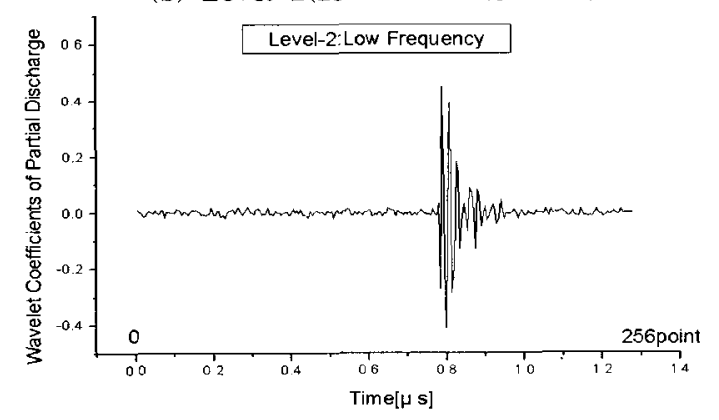

(c) Level-2(12.5 $\mathrm{MHz} \sim 0 \mathrm{~Hz})$

Fig. 9. Results of the wavelet transform level analysis of No. 3 winding faulty signals.
Figure 8 presents the results of the application of a wavelet transform level-2. In the case of the creeping discharge, it was evident that there was a type of signal, which was generated from a high frequency region, compared to other faults, which presented no signals generated from a high frequency region. In the results of the spectrum analysis, the spectrum was in the range of $0 \sim 50 \mathrm{MHz}$. In the case of the application of a wavelet transform level-1, the high frequency region presented in Fig. 9(a) was regarded as 1,024 points for the signal waveform of the marking section presented in Fig. 8. It showed a frequency separation, which was ranged as about $25 \sim 50 \mathrm{MHz}$. Figure 9(b) presents the frequency spectrum in the high frequency region, $25 \sim 12.5 \mathrm{MHz}$, by applying a wavelet transform level-2. Figure 9(c) presents the waveform in the low frequency region, 0 $12.5 \mathrm{MHz}$, by applying a wavelet transform level-2. The quantified values of SK and $\mathrm{KU}$ presented the same values in Fig. 9(a), (b), and $(\mathrm{c})$.

\subsubsection{No. 4 (1-Turn short fault signal)}

This case assumed an actual fault that presented 1 single line short. The thin insulation for each turn prevented the short between turns, and the voltage, which was produced between turns, may present only a few tens of volts in the normal operation state. However, because large or small void faults occurred at the interface between the turn insulation and the main insulation due to the complex stress generated by thermal and mechanical factors according to a certain manufacturing fault and a long time of operation, there occurred a partial discharge when a type of electrical stress was applied in a large scale at the stressed region. The partial discharge produces some erosion in insulation materials, and causes a rapid deterioration due to the short between turns. The main insulation materials can resist such a partial discharge for a few years, but the insulation material between turns can be easily dissolved in a short time of deterioration because it has a 


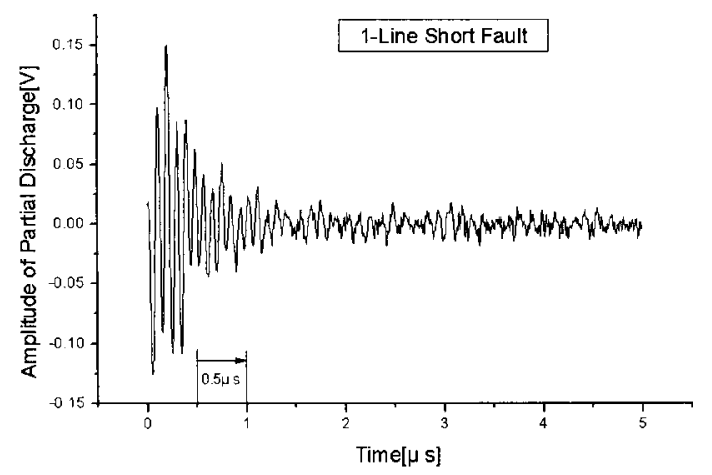

(a) Pulse waveform of the 1-line short winding

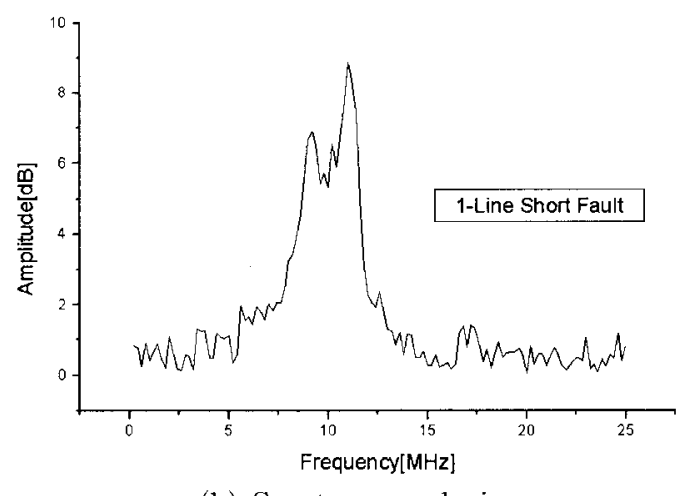

(b) Spectrum analysis

Fig. 10. PD pulse waveform and FFT analysis of the 1-line short winding.

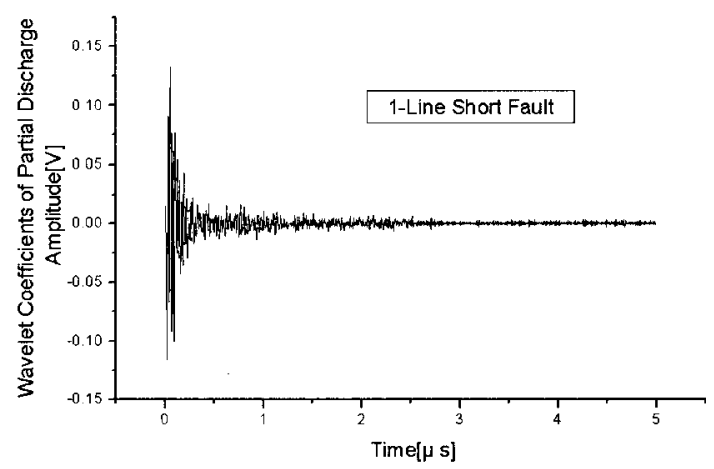

Fig. 11. Results of the application of a wavelet transform for the waveform shown in Fig. 10(a) $(\mathrm{SK}=3.66, \mathrm{KU}=15.4)$.

small discharge resistance. Thus, the turn will be shorten in the normal operation state due to the weaken insulation between neighbored turns, and the insulation was also broken due to the heat generation. Based on this insulation breakage, a study on the 1-line short was conducted.

Figure 10(a) presents a partial discharge waveform of a 1-line short winding in a time domain. The duration time was about $1 \mu \mathrm{s}$ in this case and was about $2 \mu \mathrm{s}$ and $0.5 \mu \mathrm{s}$ for the normal winding and creeping discharge, respectively. However, there were some different cases for the internal discharge due to the continuous generation of the multiple pulse waveform. Although this case simply simulated a 1-line short, there was no difference between this case and the normal state of the winding in the early stage of deterioration. In addition, it is evident that a multiple signal pulse will be generated from the different type of faults between the normal state and the 1-line short according to the progress of the deterioration. Figure $10(\mathrm{~b})$ presents the results of the spectrum analysis in a frequency domain. The frequency range was $5 \mathrm{MHz} \sim 15 \mathrm{MHz}$, and the central frequency was $10 \mathrm{MHz}$ as the largest dominant section. Figure 11 presents the results of the application of a wavelet transform level-2 for the partial discharge waveform. The SK and KU were 3.66 and 15.4, respectively. It was evident that if the duration time is long, the skewness will be shorten. In addition, the skewness will be decreased when two more pulses were superimposed.

\subsubsection{No. 5 (Non-corona tape discharge)}

Corona tapes are not used in the stator production under $3 \mathrm{kV}$ of motors and only used in motors more than $6 \mathrm{kV}$ of high voltage products. If the voltage more than $3 \mathrm{kV}$ was applied to a motor without corona tapes, the pulse scale and number of pulses significantly increased compared to other faults.

Figure 12(a) presents a partial discharge waveform in a time domain for the faulty winding without corona prevention tapes. The partial discharge pulse waveform was damped as a form of exponential function with the duration 


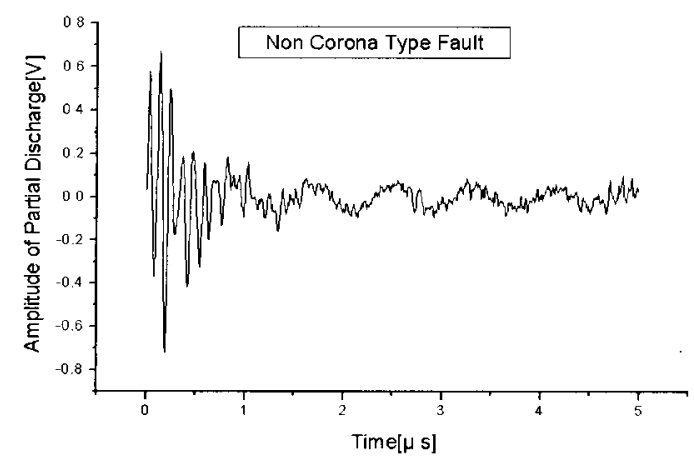

(a) Partial discharge waveform in a time domain

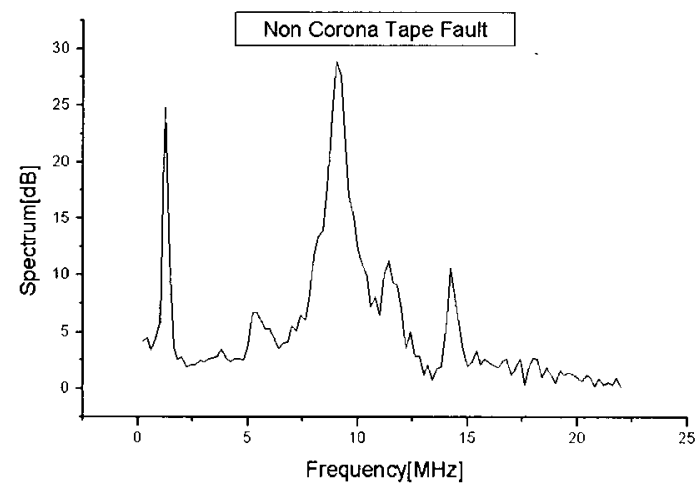

(b) Spectrum analysis in a frequency domain

Fig. 12. Partial discharge waveform for the simulated faulty winding without corona tapes.

time of $1 \mu \mathrm{s}$ as well as the 1-line short fault and was oscillated at the around of zero cross. Figure 12(b) presents the frequency characteristics of the transformation from the partial discharge pulse waveform in a time domain to the function in a frequency domain. Based on these results, the characteristics of two dominant sections were investigated. The first frequency spectrum was $1 \sim 1.6 \mathrm{MHz}$, and the second frequency spectrum was $7.2 \sim 15 \mathrm{MHz}$. The first spectrum represents the frequency at the oscillation section, and the second spectrum represents the frequency transformation of the waveform that was damped as a manner of an exponential function. Figure 13 presents the wavelet transformation of the partial discharge pulse waveform presented in Fig. 12(a) where the

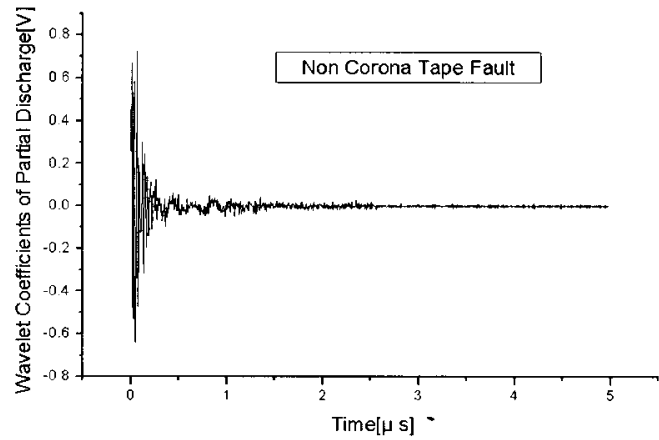

Fig. 13. Results of the application of a wavelet transform for the waveform shown in Fig. 12(a), (SK=3.5, $\mathrm{KU}=13)$.

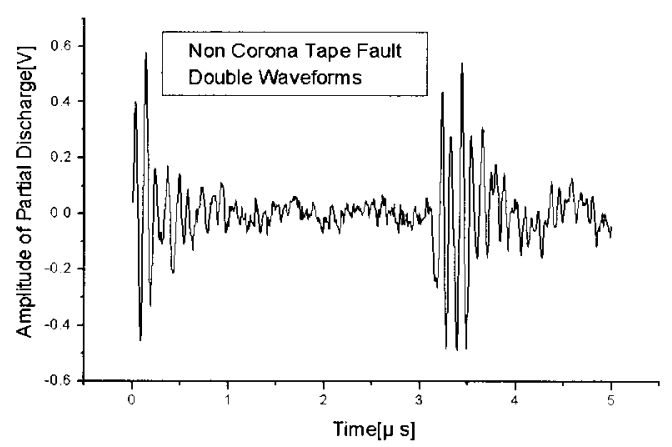

(a) Superimposed and duplicated partial discharge pulse waveform

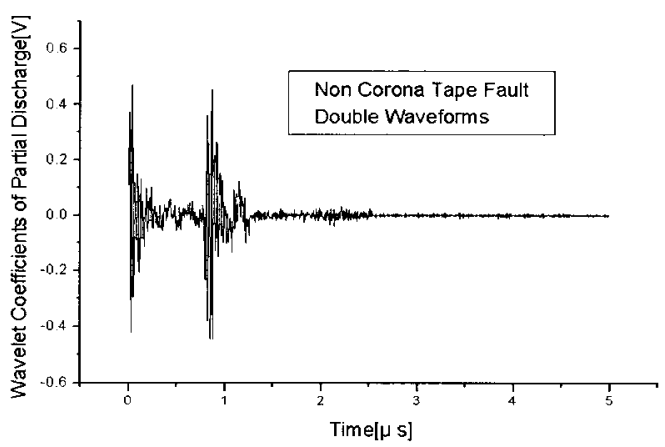

(b) Wavelet transformation level for the superimposed waveform

Fig. 14. Application of a wavelet transformation for the superimposed pulse waveform $(\mathrm{SK}=2.42, \mathrm{KU}=5.78)$.

values of SK and KU were 3.5 and 13, respectively.

Figure 14(a) presents the superimposed wave- 
Table 1. Extraction of the skewness and kurtosis for the partial discharge pulse waveform of the simulated faulty winding.

\begin{tabular}{|c|c|c|c|c|c|c|}
\hline $\begin{array}{c}\text { Types of Fault } \\
\text { Statistical } \\
\text { Parameters }\end{array}$ & No. 1 & No. 2 & No. 3 & No. 4 & \multicolumn{2}{|c|}{ No. 5 } \\
\hline Skewness & 3.27 & 2.6 & 5.4 & 3.66 & $\begin{array}{c}\text { Single } \\
\text { Pulse }\end{array}$ & 3.5 \\
\cline { 4 - 6 } & 11.86 & 8.1 & 31.4 & 15.4 & $\begin{array}{c}\text { Double } \\
\text { Pulse }\end{array}$ & 2.4 \\
\hline Kurtosis & 13 Pulse & 13 \\
\hline
\end{tabular}

Table 2. Characteristics of the frequency for simulated Windings for 5 different types.

\begin{tabular}{|c|c|}
\hline Faulty Types & Frequency Band \\
\hline No. 1 & $2.5 \mathrm{MHz} \sim 15 \mathrm{MHz}$ \\
\hline No. 2 & $7.5 \mathrm{MHz} \sim 13 \mathrm{MHz}$ \\
\hline No. 3 & $8.8 \mathrm{MHz} \sim 50 \mathrm{MHz}$ \\
\hline No. 4 & $5 \mathrm{MHz} \sim 15 \mathrm{MHz}$ \\
\hline No. 5 & $1 \mathrm{MHz} \sim 1.6 \mathrm{MHz}, 7.2 \mathrm{MHz}, 15 \mathrm{MHz}$ \\
\hline
\end{tabular}

form of two partial discharge pulses when the corona prevention tape was removed. The duration time for each pulse was a $1 \mu_{\mathrm{s}}$ pulse waveform.

For this result, T. Brosche et al.[8] reported that a partial discharge could be formed as a very small space between multiple pulses $(\sim 1$ ns to $\sim 2 \mu \mathrm{s}$ ) that can easily be superimposed for each other. In addition, because all pulses were generated in the range of the pulse response of a band pass filter, it can be integrated during the measurement of charges.

Figure 14(b) presents the results of the application of a wavelet transform for the waveform shown in Fig. 14(a). In the case of the superimposed pulse with $\mathrm{SK}=2.42$ and $\mathrm{KU}=5.78$, it presented almost the same result as the skewness and kurtosis in the internal discharge. It showed a decreased value in asymmetric level and a lowered value in the concentration of distribution.

Based on these results, the characteristics of the partial discharge pulse waveform for a normal winding and four different simulated faulty windings were noted in Table 1.

\subsection{Classification of faulty signals $[3,6,9,10]$ 3.2.1 Data processing}

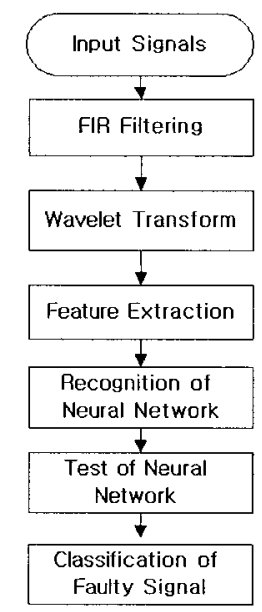

Fig. 15. Diagram for data processing.

\subsubsection{Architecture of a neural network}

The neural network used in this study was a type of multi-layered architecture, and consisted of an input layer, hidden layer, and output layer. The input layer was equaled with the number of neurons in the input layer where the feature extracted results were inputted from the one normal winding and four faulty signals. No. 1 ănd No. 2, No. 3, No. 4, No. 5 . Faulty signals were used as the type of faults. The number of neurons for the hidden layer can be classified and output using six cross verifications.

A training set for each fault was configured by 50 patterns for No. 1, No. 2, No. 3, No. 4, and No. 5, respectively, and the convergence was achieved when values of the sum square error (SSE) of the neural network was determined as a certain minimum value. This means accumulated errors for a single epoch after applying the feedback once for all training patterns, and the number of epoch was determined for the convergence. 


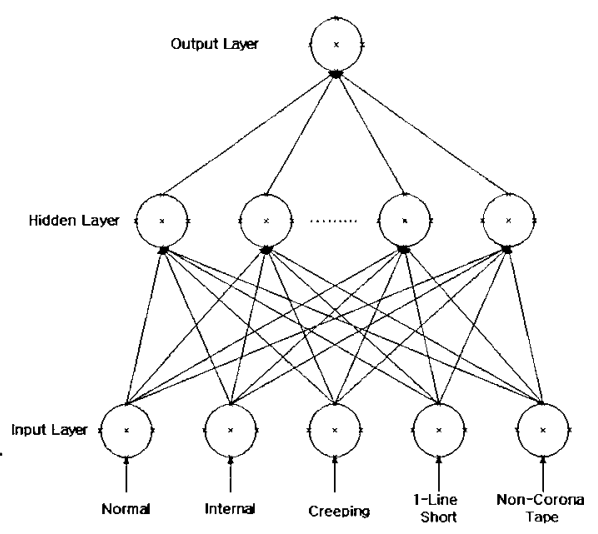

Fig. 16. Architecture of a neural network.

\subsubsection{Test for the classification of faulty signals}

Based on a preprocessing stage for each fault type (maximum value, minimum value, distribution, skewness, and kurtosis), 10 signals were used to test each feature extracted pattern signal after improving the recognition rate of 0.8 , offset of 0.65 , and momentum constant of 0.62 . The objectives for each faulty signal were No. 4: 0 , No. 2: 0.25 , No. 3: 0.5 , No. $1: 0.75$, and No. 5: 1.0 , and the classification was performed as the recognition rate from 88 to 100 .

$$
\text { R.M.S.E }=\sqrt{1 / N \sum_{k=1}^{N}(T(k)-O(k))^{2}}
$$

where $\mathrm{N}$ is the number of data used in the test, $T(k)$ is the output of an actual data, and $O(k)$ is the estimated value from the identified model. It is possible to present the calculated learning error curve using Eq. (1) based on the identified data.

\section{CONCLUSIONS}

This study investigated the insulation used in a high voltage motor, which requires high starting currents and power due to the operational characteristics. In addition, there are possibilities of some weakness and destruction in the insulation due to the electrical and mechanical stress in the winding of motors for
Table 3. Test results of the neural network.

\begin{tabular}{|c|c|c|c|c|c|}
\hline \multirow{2}{*}{ Number } & \multicolumn{5}{|c|}{ Target Values } \\
\cline { 2 - 6 } & No4 & No2 & No3 & No1 & No5 \\
\hline 1 & 0.00000 & 0.25000 & 0.50000 & 0.75000 & 1.00000 \\
\hline 2 & 0.00000 & 0.25000 & 0.50000 & 0.75000 & 1.00000 \\
\hline 3 & 0.00000 & 0.25000 & 0.50000 & 0.75000 & 1.00000 \\
\hline 4 & 0.00000 & 0.25000 & 0.50000 & 0.75000 & 1.00000 \\
\hline 5 & 0.00000 & 0.25000 & 0.50000 & 0.75000 & 1.00000 \\
\hline 6 & 0.00000 & 0.25000 & 0.50000 & 0.75000 & 1.00000 \\
\hline 7 & 0.00000 & 0.25000 & 0.50000 & 0.75000 & 1.00000 \\
\hline 8 & 0.00000 & 0.25000 & 0.50000 & 0.75000 & 1.00000 \\
\hline 9 & 0.00000 & 0.25000 & 0.50000 & 0.75000 & 1.00000 \\
\hline 10 & 0.00000 & 0.25000 & 0.50000 & 0.75000 & 1.00000 \\
\hline \multicolumn{5}{|c|}{ Test Results } \\
\hline 1 & 0.00031 & 0.24966 & 0.50001 & 0.74909 & 1.00000 \\
\hline 2 & 0.00076 & 0.24960 & 0.50001 & 0.74882 & 1.00000 \\
\hline 3 & 0.00009 & 0.24987 & 0.50001 & 0.75076 & 1.00000 \\
\hline 4 & 0.00041 & 0.24982 & 0.50001 & 0.74973 & 1.00000 \\
\hline 5 & 0.00016 & 0.24969 & 0.50001 & 0.75033 & 1.00000 \\
\hline 6 & 0.00030 & 0.24984 & 0.50001 & 0.74998 & 1.00000 \\
\hline 7 & 0.00029 & 0.24978 & 0.50001 & 0.74991 & 1.00000 \\
\hline 8 & 0.00018 & 0.24997 & 0.50001 & 0.74926 & 1.00000 \\
\hline 9 & 0.00030 & 0.24999 & 0.50001 & 0.75137 & 0.99992 \\
\hline 10 & 0.00079 & 0.2490 & 0.50001 & 0.74934 & 1.00000 \\
\hline
\end{tabular}

an extended period of operation. In the case of the fault in stator windings of a high voltage motor, it induces a certain level of destruction in insulations. This will lower the reliability in power supplies, stop the generation of electricity, and bring huge economic losses.

The fault that may occur in the stator winding of a motor in an actual field was simulated and measured as a partial discharge pulse waveform using an epoxy/mica coupler. The feature of the measured signal was extracted using statistical parameters that were applied using a wavelet transform method. The feature extraction of five different simulated faulty signals was used as a preprocessing stage for the input of a neural network. It was evident that the type of faulty signals can be classified from the test results using faulty signals that were randomly selected from the signal, which was not applied in the training after the training and learning, by applying it to a backpropagation algorithm due to the supervising and 
learning method in a neural network in order to classify the faulty type. It becomes an important basis to study diagnosis methods using the classification of faulty signals with a feature extraction algorithm, which can diagnose the fault of stator windings in the future.

\section{ACKNOWLEDGEMENT}

This work has been supported by KESRI ( $\mathrm{R}-2003-\mathrm{B}-447$ ), which is funded by MOCIE (Ministry of commerce, industry, and energy).

\section{REFERENCES}

[1] Y.-J. Kim, D.-H. Hwang, B.-C. Shin, D. ${ }^{-}$Y. Park, and J.-W. Kim, "Development of continuous partial discharge monitoring system for generator stator insulations", Conference Record of the 2000 IEEE International Symposium on Electrical Insulation, Anahcim, CA USA, p. 5, 2000.

[2] G. C. Stone and H. G. Sedding, "In-service evaluation of motor and generator stator winding using partial discharge tests", IEEE Trans. on Industry Applications, Vol. 31, No. 2, p. 299, 1995.

[3] J. P. Zondervan, E. Gulski, and J. J. Smit, "Fundamental aspects of $\mathrm{PD}$ patterns of on-line measurements on turbogenerators", IEEE Transactions on Dielectrics and Electrical Insulation, Vol. 7, No. 1, p. 59, 2000.
[4] G. Stone, "Importance of bandwidth in PD measurement in operating motors and generators", IEEE Trans. on Dielectrics and Electrical Insulation, Vol. 7, No. 1, p: 6, 2000.

[5] J.-J. Park, D.-J. Kwon, Y.-C. Song, and C.-B. Ahn, "A study on feature extraction of transformers aging signal using discrete wavelet transform technique", Trans. KIEE, Vol. 50C, No. 3, p. 121, 2001.

[6] J.-J. Park and Y.-C. Song, "A study on diagnosis of transformers aging state using wavelet transform and neural network", J. of KIEEME(in Korean), Vol. 14, No. 1, p. 84, 2001.

[7] G. J. Paoletti and A. Golubev, "Partial discharge theory and technologies related to medium-voltage electrical equipment", IEEE Application, Vol. 37, No. 37, p. 90, 2000.

[8] T. Brosche, W. Hiller, and E. Fauser, "Novel characteristic of PD real-time measurement of pulse parameters", IEEE Trans. Electrical Insulation, Vol. 6, No. 1, p. 51, 1999

[9] W. Wang, K. Tan, K. Gao, and W. Gao, "Optimal Feature Extraction for Partial Discharge Recognition", Project(No. 5963 7200)supported by NSFC and NEEPC, p. 115,2000

[10] K. Gao, K. Tan, and F. Li, "PD pattern recognition for stator bar models with six kinds of characteristic vecotors using BP network", IEEE Trans. on Dielectrics and Electrical Insulation, Vol. 9, No. 3, p. 381, 2002. 